\title{
Health Physics
}

National Cancer Institute

\section{Source}

National Cancer Institute. Health Physics. NCI Thesaurus. Code C16667.

The scientific discipline that evaluates the effects of ionizing radiation and the conditions for its safe use. 